\title{
Cross-Dressing as Transvestism in Children's Literature: An Analysis of a 'Gender-Performative' Model
}

\author{
Victoria Flanagan
}

$r^{r}$ ross-dressing in its various forms is frequently depicted in film, television and literature, and habitually misunderstood. Cultural criticism of the twentieth century has sought to destabilise the difference between the sexes, in a bid to establish the social construction of gender identity. The resulting debate has placed cross-dressing/transgendered subjects in an awkward position: understood by certain elements of the academic fraternity; misunderstood by the public of which they are 'othered' members. Children's literature provides an interesting facet to this ongoing conceptual dilemma. Contrary to popular expectation, cross-dressing is extraordinarily prevalent in literature produced for children. It is evident within a wide and culturally divergent range of children's iiterature, including traditional tales told by the Brothers Grimm; seventeenth century French fairy tales; folktales from Russia, the Balkans and the Middle East; contemporary children's novels; and animated Disney feature films. It is utilised by authors for a range of purposes that share much thematic commonality, despite the fact that the texts in which it occurs differ greatly from one another in terms of cultural context, historical positionality and literary genre. Interestingly, cross-dressing appears in literature published long before the modern reconceptualisation of childhood and its concomitant willingness to allow children to be exposed to issues of sexuality and gender more usually associated with adult life. The use of crossdressing in children's literature has, however, never been questioned or censured. It has simply been accepted and even encouraged as an aspect of the cultivation of imaginative powers and the positive role attributed to this process in literature for children.

The prevalence of cross-dressing in children's literature is such that it can be categorised into a number of paradigmatic schemata. The cross-dressing models most commonly found in children's literature are the antithesis of the contemporary cultural concept of transvestism, with one exception. These models can be identified as: female-to-male, as in the 'adventure' paradigm of the animated Disney film Mulan and Tamora Pierce's Alanna; male-to-female - a more rarely occurring model, evident either in the form of provocative and socially rebellious French salon fairy tales such as "The Counterfeit
Marquise"t or a brief, comic interlude of the type found in tales such 'Little Red Riding Hood' (the wicked wolf dressing himself in the clothes of an old woman) or in episodes such as Toad's escapades as a washerwoman in The Wind in the Willows; or, finally, as a mirror of the issues prevalent in contemporary transgenderism, the only example of which is the unusual Swedish novel Johnny, My Friend, by Peter Pohl.

For the purposes of this paper I have chosen to focus my discussion on four children's cross-dressing texts: the Disney film Mulan; Tamora Pierce's Alanna, the first volume of her 'Song of the Lioness' trilogy; the seventeenth century French fairy tale, 'The Subtle Princess' ${ }^{2}$ and the Middle Eastern folk tale 'The Mouse, The Thing and The Wand'. ${ }^{3}$ Each of the cross-dressing episodes within these texts pertains to the female-to-male children's cross-dressing model, which I have chosen to take as my focus for this article - primarily because it is the most commonly occurring of all the children's crossdressing schemata and the one which lends itself most easily to paradigmatic analysis through its use of identifiable narrative themes and strategies. The recurring nature of the female-to-male children's cross-dressing model is due to the prevalence of patriarchal social structures in both the literary realm and historical actuality; the patriarchal context provides an arena in which the female heroine can succeed most magnificentiy and effectively by becoming (through the transvestic process), and then overshadowing, the very sex responsibie for denying her agency. Mulan, Alanna, 'The Subtle Princess' and 'The Mouse, The Thing and The Wand' each revolves around an oppressed female protagonist who is able to escape the confines of her sex by disguising herself as a male (this decision is actually made by the central character's mother in 'The Mouse, The Thing and The Wand'). The feminist concerns apparent within these particular cross-dressing narratives are perhaps the most palatable (and therefore acceptable and 'explicable', in terms of being read to children) to adults playing a supervisory role in the process of choosing appropriate literature for younger readers. The reason for this acceptance is clear: the female-to-male 'cross-dressing' evident in children's literature is not actual cross-dressing. It is simply a form of disguise. It is innocent and de- 
sexualised. It allows a character of one gender (feminine) to experience life as the 'other' for a brief period of time, but only in order to achieve something specific. Such literary representations coincide with a common childhood pleasure in dressing up and pretending to be someone else, and both might be deemed to constitute a normal part of childhood.

By utilising the phenomenon of cross-dressing, children's literature which conforms to the female-to-male paradigm interrogatively examines the socialiy constructed notion of gender, facilitating a re-evaluation of the socially prescribed notion of gender across an array of cultural, historical and genre-related divides. Cross-dressing claracters within this female-to-male convention disrupt gender conventions through their successful adoption of the physical signifiers of sex appropriate to their biologically gendered opposites. In achieving a 'change of sex', these characters demonstrate the fallibility of gender codes and assumptions relating to the constitution of masculinity and femininity, necessitating a re-thinking of gender and its role in the construction of individual identity.

Children's cross-dressing narratives which conform to the female-to-male paradigm unfold according to a schema which is probably the most established of all the children's cross-dressing models, and from which there is the least variation. The paradigmatic structure of the female-tomale children's cross-dressing model takes the following form: Firstly, the cross-dressing subject is female but occupies a state of 'othered' femininity. She is biologically female, but is ostracised from this gendered group for a plethora of reasons relating to her gendered nonconformity. Secondly, her cross-dressing is not sexually motivated. Her appropriation of masculine clothing is enacted out of necessity, rather than an attraction to the actual garb and its social connotations of masculinity. The eroticism usually associated with cross-dressing is absent, as too is the theatricality - inviting the possibility of being caught out or exposed is not high on the heroine's agenda, as the repercussions could be disastrous. Crossdressing is embarked upon as an adventure and journey of self-discovery, as opposed to the fulfilment of a sexual desire. Thirdly, the issue of a convincing performance of gender (illustrated by the commonly posed question of whether a transvestite can 'pass' for a wo/man) is reappropriated by the relevant children's literature into an issue relating to masculine or feminine 'tasks' and 'feats'. Whether cross-dressed subjects can pass in visual terms for their gendered opposites is not significant - they quite simply do. The focus lies on whether they can behave like a man or woman, successfully performing that which has previously been denied to them. Finally, the female-to-male cross-dressing model in children's literature is usually subject to temporal restrictions. It is not an ongoing occurrence, as in the case of most contemporary transvestites. Once it has occurred, and its purpose realised (in the sense of self-awakening) the subject's former gender position is resumed. The resumed gender position, however, is one which is based on an acquisition and accumulation of both male and female gender characteristics, and which is operative as a 'third" classification of gender.

Although the female-to-male cross-dressing schema is the most developed of the children's literary cross-dressing models, it does not apply in entirety to the four texts in question. Mulan and Alanna closely follow its structure, but deviations are apparent in 'The Subtle Princess' and 'The Mouse, The Thing and The Wand'. These divergences are generally a result of the fact that this cross-dressing model, like the other existing models, traverses a broad range of literary genres and cultural contexts. Despite these variations, it is still possible to classify texts such as 'The Subtle Princess' and 'The Mouse, The Thing and The Wand' in the female-to-male cross-dressing model because of the manner in which these narratives, alongside the texts Mulan and Alanna which follow the paradigm directly, reconceptualise gender as 'performative' and create a third category of gender that stands outside of the conventional notions of masculinity and femininity. This reconceptualisation of gender is the uniting element of narratives within the female-to-male children's cross-dressing paradigm, and an analysis of it will form the basis of this paper. The reevaluation of the concept of gender evident in this crossdressing model manifests itself in the cross-dressing heroes'/heroines' apparent ability to change their gender 
at a certain textual point, walking in and out of various gender roles as if they were merely actors changing characters for various theatrical performances. This ability accords with many of the theoretical principles evident in Judith Butler's controversial and much-heralded work on gender theory, Gender Trouble (1990). Gender Trouble is based on the theoretical argument of gender as performance, and it is to varying nuances of this theory that the female-to-male children's cross-dressing model subscribes. Butler's analysis of gender offers an insightful theoretical tool for examining the female-to-male children's cross-dressing paradigm, as her self-professed purpose (as indicated in the preface to Gender Trouble) is 'to trace the way in which gender fables establish and circulate the misnomer of natural facts' (p.xiii). It is precisely against these gender fables that the subjects of cross-dressing narratives in children's literature react, debunking traditional myths regarding the essential and so-called 'innate' attributes of male and female genders. It is necessary to mention at this point, however, that Butler's arguments are not wholly applicable to the female-to-male cross-dressing schema in children's literature, which is not so radical as to suggest that 'gender' should be conceived in such a boundary-less and subjective fashion specifically because this narrative model can only operate in a world in which gender is polarised, and to which a number of cross-dressing characters return with a degree of contentment. Rather than critically examining Butler's work, or discussing its wider cultural reception, its inclusion in this article is primarily to establish a link between Butler's radical gender theory and the representation of female-to-male cross-dressing in children's literature. For this reason I have chosen to limit the focus to Butler's Gender Trouble and the issues raised within this text that are relevant to the portrayal of cross-dressing in children's literature, such as Butler's notion of gender as a form of impersonation or 'performance', and the suitability of this theory to a children's cross-dressing context where gender is invariably constituted as 'performance' and the physical realities of transvestism are rendered insignificant in the representation of a particular character's transvestic experiences.

Female-to-male cross-dressing narratives in children's literature question socially assumed understanding in relation to gender by playfully exposing the redundancies of two, polarised gendered identities, and gently ridiculing the limitations that such a system essentially imposes on supposedly autonomous individuals. The cross-dressing narratives on which I focus begin their process of gender re-evaluation through the portrayal of a character to whom certain gendered stereotypes do not apply. In the fantasy text Alanna, the centrai character is a female who lusts after adventure and other traditionally masculine pursuits which are unattainable for women according to her society's gender codes:

'D'you think I want to be a lady?' his sister asked. 'Walk slowly, Alanna,' she said primly. 'Sit still,

Alanna. Shoulders back, Alanna. As if that's all I can do with myself!' She paced the floor. 'There has to be another way.'

(1983, p.1)

To escape the sedentary feminine life deemed culturally appropriate to her biological status, Alanna chooses to don the clothes of a male and actively change (or temporarily re-route) her gendered destiny. In Mulan, a corresponding pattern emerges. Mulan is a dutiful daughter who simply can't seem to achieve femininity. She performs dreadfully in the culturally all-important encounter with the matchmaker, disgracing herself in the eyes of her parents and small village community. An opportunity for her to reinstate herself beckons when news of an imperial decree, demanding that all families enlist their sons, or in the absence of such, fathers, in the royal army reaches her village. Mulan is brother-less, and in order to prevent the enlistment of her elderly father she disguises herself and joins the army in his place. Filial piety determines her decision, but it is her 'othered' identity (in terms of traditional femininity) that enables her to succeed in assuming a male persona. Similarly, Finessa, the feisty heroine of 'The Subtle Princess', occupies a position outside of conventional femininity. Unlike Alanna and Mulan, Finessa clearly fulfils a model of feminine perfection, evident in her talents for music, sewing and dancing; yet she also embodies qualities that elude categorisation due to their masculine orientation: her intelligence, perspicacity and aptitude for political 
negotiation and diplomacy. Rahat, the feisty heroine and hero of the tale 'The Mouse, The Thing and The Wand' is perhaps the most exceptional outsider of these protagonists. Frustrated by the restrictions and constraints imposed upon her own life, Rahat's mother determines to give her child the best opportunities life has to offer which means that she is raised as a boy. Despite this, Rahat is painfully aware of the fact that he/she is different from his/her male playmates and the other women and girls who inhabit the village. Rahat is effectively estranged from either conventional gender category, yet is highly desirous of genuine masculinity (that is, masculine genitalia, which is all she feels that she needs in order to become an authentic male). Initially, Rahat seems relatively content with his/her strange fate until a chance meeting changes this perspective: Rahat falls in love. The institution of marriage is denied to Rahat because of his/her indefinable gender status. Refusing to be condemned to a solitary life, Rahat resolves to fight for his/her love, and in doing so is awarded that which she so greatly desires - an authentically male gender - when her magical horse rewards her great deeds with male genitalia.

Each of the texts mentioned above assumes a preliminary position in which gender is the primary concern, a result of the fact that the represented characters do not accord with (and are 'failures' when held up against) the culturally recognised signifiers of gender. From this introductory unease with conventional notions of gender, each text unravels to reveal a moment of decision, or action, in which the central characters redress their gendered discomfort by rejecting that which they do not, or cannot, aspire to and embracing the outward signifiers of that to which they do. This is not to say that each cross-dressing character aspires to be a 'man', as such. What they desire, in most cases, is the freedom which masculinity offers. In exchanging sexed attires, they immediately become privy to a realm that is much less constraining, and which offers unprecedented opportunities within a patriarchal social structure. Once the physical act of changing clothes has taken place (this event is given little focus in most children's narratives), the more important aspect of 'behaviour' becomes the text's primary concern. In representing this experience, gender becomes the crucial focal point, regardless of textual variances in plot and genre. Notwithstanding a wide discrepancy in literary style, historical period, country of origin, thematic concerns and textual genre, the essential core of these narratives is an analysis and fundamental questioning of gender itself. As these cross-dressing characters breast the gender divide by adopting the clothes of their biologically sexed opposites, they embark upon an exploration of all those things assumed to pertain to a particular gendered identity, and in the process discover that many such behavioural patterns and seemingly innate characteristics are anything but 'natural' or inherent. Through their own initiative and powers of observation, a realisation of the illusory nature of gendered attributes emerges as both protagonist and reader are made aware that the possibility of challenging one's biological sexual status does indeed exist, and can be achieved with triumphantly successful results.

The seeming ease with which cross-dressing characters transgress gender definitions and boundaries, convincing others of the 'authenticity' of their gendered performances, contributes to the representation of gender in children's cross-dressing narratives as a 'regulatory fiction', to use the words of Judith Butler (1990, p.141), as opposed to the less-challenging concept of 'sex' and the advocacy of sexual equality. It is precisely in relation to this issue that children's cross-dressing narratives offer the reader a unique perspective on gender. The texts in question do more than promote feminist empowerment at the cost of masculinity. Cross-dressing narratives which conform to the female-to-male paradigm interrogate cultural assumptions and deconstruct the pervasive gender myths responsible for the construction of a socially coherent gendered identity. At the same time, they actively provide an alternative paradigm of gender which is not limited to only two, oppositional frameworks, but recreated and reworked into an individualistic concept that supersedes socially imposed frameworks and boundaries. The constructed nature of gender is made transparent, and it is this transparency which enables a 'change' of gender by way of assuming a 'different' gendered performance. Armed with the knowledge of what it is that constitutes a masculine-gendered (or female-gendered) subject position, cross-dressing characters can effectively alter their gender. In doing so, they emphasise the artificiality 
of gender categories and divisions as they seek to reproduce them in their own individual performance. Each crossdressing character is actively engaged in a process of deconstruction and revision. On one level, gender constructs and classifications are maintained. On another, a new gender 'code' is born and given life by the crossdressing subject - one that combines some traditional gender elements, rejects others, and essentially resists categorisation. In changing their clothes and gendered identity, these heroines/heroes challenge the very fabric of gender constructions. Cross-dressing characters within the female-to-male schema create what could be considered a 'third' realm, in which gender can be manipulated into something liquid and malleable. It can shift according to a person's behaviour in a particular circumstance, enabling them to walk in and out of the shadows of conventional masculinity and femininity, adopting both male and female 'sexed' bodies.

The performative nature of gender becomes the most significant denotation of gender identity in children's female-to-male cross-dressing narratives, and is far more critical than the outward, physical characteristics which are usually perceived to construct a subject's sex. One obvious reason for this is that literature is based not on visual images, but on language. The dilemma of most contemporary adult cross-dressers - that of visually passing for another gender - is absent in children's literature. While clothing and appearance are important, they are not solely responsible for creating the illusion of gender. The issue of passing is not often raised, as once a character assumes a different gender identity there is a general textual acceptance of this fact. The reader is not plagued with questions of, 'Does this character really look like a boy?' or 'Does this character look 'masculine' enough to be convincing?' Instead, it is assumed that the character does look convincing, and the narrative proceeds from this point. The majority of children's texts which contain a cross-dressing theme spend little or no time describing the newly-adopted attire of the cross-dressing character. The real issue is whether the character can act like a boy (or a girl), and if she (or he) is able to perform, then the ultimate concern of the remainder of the story is for how long she (or he) can maintain the performance without detection. That the character can be assumed to look authentic is facilitated by the fact that physical gender divisions are not as clearly articulated in children as in adults. The defining physical characteristics of gender - breast and hip development in women; facial and body hair in men - are not present in pre-pubescent children. In Alanna, for example, the female heroine switches places with her brother to become a knight. Their physical differences are minimal:

Thom and Alanna Trebond were twins, both with red hair and purple eyes. The only difference between them - as far as most people could tellwas the length of their hair. In face and body shape, dressed alike, they would have looked alike. (p.1)

It is interesting to note that Alanna is one of the few children's cross-dressing texts that attempts to deal with the issue of physicality. Pierce refers, on more than one occasion, to the bandaging of Alanna's breasts, in order to conceal them. These same curves eventually lead to her public disclosure at the end of Book Two, when her corset is slashed and her breasts show through her shirt (p.225). Alanna's first experience of menstruation is also mentioned, becoming the central issue in a particular chapter. This interlude is relatively exceptional in terms of ther examples of cross-dressing in children's literature, most of which choose not to deal with the stark realities of a girl masquerading as a boy and the pubescent difficulties such a scenario presents. This incident also prefigures a development from childhood, where crossdressing can be successfully achieved because of the physical similarities between pre-pubescent boys and girls, to adulthood, where the many dilemmas of contemporary adult transvestism and transsexualism begin to encroach on an otherwise simple and straightforward text. Pierce adeptly handles the challenge by bringing the issue of puberty and the gendered physical changes it entails to the forefront of her text. At the same time, however, Alanna is provided with certain friends who can aid her through her gendered rites of passage without giving away the secret of her identity. The result is a text which illuminates the difficulties experienced by a crossdressing character, rather than ignoring the problematic physical issues which would ordinarily arise in such a context, but which also emphasises the fact that only a 
select group of characters are aware of Alanna's predicament. The others simply accept her as a boy, and are continually impressed by her natural skills and aptitude for masculine behaviours. It is this behavioural aspect of gender that Pierce chooses to emphasise in her text, and her focus throughout remains firmly entrenched on Alanna's conduct, rather than her appearance. Alanna's success as a male depends on such a focus.

The absence of focus on physicality apparent in most cross-dressing texts therefore assists the development of cross-dressing themes in children's literature, further delineating the distinction between female-to-male crossdressing in children's literature and the contemporary conceptualisation of transvestism in an adult setting, where the risks of detection are considerably higher and thus of paramount significance. Children's cross-dressing texts assume that the visual presentation of the crossdressed character will immediately be accepted as convincing by the younger reader (due maybe to the suspension of disbelief required for most children's literature). This phenomenon is most acutely realised in Mulan, where the masculine Mulan is drawn in a significantly different manner (eyebrows thicker; more square-looking jaw; smaller eyes and less-full lips) from the feminised Mulan. Where the text does not explicitly focus on physicality, it instead focuses on an analysis of gender that goes beyond superficial surfaces (that is, physical presentation) to examine the way in which gender is constructed on a more complex, behavioural level. Texts such as Alanna, Mulan and 'The Mouse, The Thing and The Wand' clearly illustrate this poirt. The central characters of these texts are young girls, living in historically patriarchal worlds that severely restrict women. Cross-dressing is viewed as a means through which freedom and seif-discovery can be achieved. As 'boys', these characters are able to access domains and opportunities traditionally denied to women, such as the training school for young knights, in Alanna; the king's army, in Mulan; and even the right to 'play', far removed from the domesticated, chore-driven role of women in 'The Mouse, The Thing and The Wand'. What they learn from their adventures is that it is indeed possible for each of them to 'become' males, an accomplishment symbolic of emancipation and self-autonomy, despite their anatomicai disadvantages. Alanna learns that her small physical stature is no impediment to her ability to wield a sword. In 'The Mouse, The Thing and The Wand,' Rahat's mother, frustrated by the restrictions and constraints imposed upon her own life, determines to give her biologically female child the best opportunities life has to offer - which means that she must be raised as a boy. Rahat discovers that an (initial) absence of a 'thing' is not detrimental, ultimately, in his/her quest for manhood and acceptance by his/her lover. Cross-dressing operates within each of these texts as a signifier of liberty and equality, and as a vehicle for self-actualisation and awakening. It restores an unprecedented equilibrium between the sexes in the context of a rigidly constructed and divided world that desperately seeks to prevent such gendered harmony. In spite of the powerful social structures which seek to curtail the activities of women, each of the characters in these texts is a testament to the power of the individual. Initially viewed as feminine 'failures', they eventually become not only impressive females, but also impressive 'males', and are valued as such by their male counterparts. Upon being discovered or 'unmasked', as eventually occurs in most narratives, cross-dressers are ultimately perceived as still 'different' from the other characters with whom they interact. Notwithstanding the issues of gender which so obviously surround them (that is, to the question of which gender do they actually belong to at any given textual point), crossdressers are positioned at a point beyond these concerns when they are finally evaluated by other characters. This is illustrated in the case of Alanna, whose biological status is discovered by Jonathan, the king's son, at the end of Book 1. His discovery of this fact, however, does not affect his friendship with Alanna, or his desire for her to be his designated squire at the palace. Alanna has already proved herself worthy of this honour, and because their relationship has been successfully established on these masculine terms, her true identity does not detract from her demonstrated capabilities:

'Before we lefi, I told him I wanted you for my squire. He didn't seem very surprised.' Jonathan wriggled, trying to find a softer spot on the 
ground.

'B-but,' Alanna stuttered, 'isn't it different? Now that you know -'

'That you're a girl? No, not in the way you mean. Girl, boy or dancing bear, you're the finest squireto-be - at Court.'

(pp.215-16)

Jonathan's words to Alanna, 'Girl, boy or dancing bear', encapsulate a central theme in children's female-to-male cross-dressing narratives. Cross-dressing, as it is used within this specific paradigm, is used to express themes of tolerance and acceptance in children's texts, specifically in relation to the issue of individual identity and the complex childhood questions which can often surround a young subject's quest for autonomy and selfhood. Children's narratives employ the female-to-male crossdressing model in a manner which effectively demonstrates the need for individuals to be judged for who they actually are, and by the unique qualities each possesses, rather than their ability to fulfil a prescribed social and/or gendered role into which they have had the ill-fortune to be born. Accordingly, the heroes and heroines of femaleto-male cross-dressing narratives are granted praise in terms of their individual achievements, irrespective of the gender guise they happen to be wearing at the time: Alanna, when she is discovered by Jonathan; Mulan, who is honoured by the Emperor; Finessa, the heroine of 'The Subtie Princess', who engenders praise most specifically from the authorial voice and, by extension, the reader; and Rahat, whose bravery wins him/her the hand of the princess. The cross-dressing process is one which also acts as a kind of personal epiphany for the individual character concerned. Initially, cross-dressing characters are constructed in terms of a deficit of femininity or masculinity. Their transvestic experiences contribute to the construction of an identity which is founded on principles of success and accomplishment - from the theatrical coup of maintaining the disguise, to the victories attained whilst it is worn. The question of gender becomes largely insignificant in relation to each of these characters and their admirable, hard-won feats. Cross-dressing characters who operate within the female-to-male paradigm transgress conventional notions of gender to the extent that previously stable gender divisions begin to blur and mutate, becoming an arbitrary and artificial classification that loses its relevance in the unravelling of the cross-dresser's story - which is, essentially, a story of both genders and of none, or of a 'third'.

It is in relation to the creation of a 'third' gender that the work of Judith Butler holds particular significance. The fact that it is possible to change one's gender is the central issue around which the conceptualisation of gender in children's female-to-male cross-dressing narratives revolves. Rather than being a fixed attribute in a person, gender becomes something of a fluid variable, subject to shifts and changes in different contexts and at different periods of time. Elements of Butler's gender theory are evident in children's female-to-male cross-dressing narratives on a number of levels. Firstly, the very fact that gender binaries are clearly defined and oppositional within these narratives makes it possible for them to be challenged and re-appropriated with relative ease. While there are vast differences between masculinity and femininity in these texts, the heroes and heroines of female-to-male cross-dressing narratives in children's literature destabilise such gender distinctions to the extent that they create an arena for themselves in which gender is turned into something malleable and free-flowing. They do this by asserting a notion of 'behavioural' gender based on performance. In order for a hero or heroine to change their gender, they must approach the situation as an actor approaches a new role. If they can behave accordingly (regardless of their physical characteristics), their newly assumed gender will not be questioned. The issue of performance is particularly crucial to crossdressing texts such as Alanna and Mulan. In both, a similar motif emerges. A young woman, dissatisfied with her lot in life, cross-dresses in order to gain entrance to a military pursuit or endeavour available only to men. The challenge presented to her is not only to 'look' like a man in terms of dress, but also to 'act' like a man. Alanna and Mulan must learn to wield a weapon with ease, as well as assuming the traditionally male attributes of aggression and self-sufficiency. The irony of their situation is that both Alanna and Mulan are triumphantly victorious in achieving a masculine-gendered persona, despite some initial hiccups in their 'opening scenes'. 
Their performances as males are more highly lauded than any of the performances given by their new gendercompatriots, who have a biological advantage over them: Alanna is the chosen page of Jonathan, the king's son, which is considered a great honour by the other male pages. Mulan, with her strategic battie tactics, is singlehandedly responsible for the defeat of the Hun army.

The central tenet of cross-dressing narratives in children's literature lies within this performative paradox: gender is not portrayed within these texts as something biologically decreed. Its socially manipulated and artificial constructs are, often with a great deal of good-natured humour, exposed in all of their frailty and held up for worldly inspection. Using Butler's reasoning it is possible to perceive the distinction between 'sex' and 'gender' in these narratives as not clearly demarcated at all. 'Sex' can be viewed, argues Butler, in equally constructed terms as 'gender', proliferated throughout various societies and generations by discursive regimes of power that maintain compulsory heterosexuality and phallogocentrism. In this context, gender is represented as 'a kind of persistent impersonation that passes as real' (p.x). Butler, describing a drag performance, refers to the hero/heroine as destabilising 'the very distinctions between the natural and the artificial, depth and surface, inner and outer through which discourse about genders almost always operates' (ibid.). While Butler is writing specifically about drag, her analysis is also appropriate to female-to-male cross-dressing in children's literature, although children's literature tends not to parody gender performances as overtly as drag. Mulan may be an exception with its depiction of men and how they 'behave', and its explicitly self-conscious reference to contemporary transvestism: Mushu, the smart-talking Chinese dragon who befriends Mulan at the beginning of her adventure and acts as her constant companion throughout the film, at one point makes a jibe about Mulan 'taking her drag show on the road'. Their effect in exposing the many constructs of the sex-gender relationship is ultimately the same. It is even possible to view children's crossdressing narratives as the more radical proponents of the 'gender as performance' theory because of their simplicity (in terms of approach) and obvious success in subverting gender. Unilike drag performances, there is no potential for misinterpretation or representative 'failure'. The fact that characters walk in and out of gender roles is indicative of the fluidity of gender within these texts - a representation that renders the notion of gender subject to a myriad of subversive manipulations.

This is not to say that it is easy to subvert gender. For in these children's texts, 'changing' one's gender is difficult and requires considerable effort and perseverance, as in the amusing scenes in which Mulan practices her swaggering masculine stance. The fact that cross-dressing subjects experience difficulty in assuming a gender role different from the one they are accustomed to playing is illustrative of the seemingly insurmountable divisions between 'masculinity' and 'femininity', but the characters' successful transition from one gender to another vividly highlights the socially constructed nature of gender divisions and creates a conception of gender in which the most significant issue is performative behaviour. If the subject approaches the issue of cross-dressing as an actor does a demanding new role, he/she can successfully 'perform' their new gender without any suspicions of their actual biological status being detected. 'Sex' becomes simply a biological feature like any other, rather than the determining characteristic of a body. Armed with the necessary social information, that is, which behaviours are considered to be masculine or feminine and hence which behaviours should be adopted and which discarded, each cross-dressing character is able to give a spectacular performance - to the extent that they 'outperform' other subjects whose 'natural' sex/gender requires a similar performance.

One way of rationalising this 'outperformance' is to consider it in terms of the characters performing in a realm that is, in a sense, outside of gender binaries. Despite the fact that each character is consciously performing one gender role at the expense of the other, subconsciously they bring elements of both genders to the role. The cross-dressing subject is able to operate outside of the two, stable gender divisions. This results in a convincing gender performance that can benefit from a knowledge of both genders, drawing on elements of both and alternating between the two. For this reason, cross-dressing characters give 'performances' that are 
perceived as 'more than usually successful' for a particularly gendered role. This achievement lies in the amalgamation of 'positive' masculine and feminine gender attributes. Alanna is highly skilled in swordsmanship, but also a great healer; she combines sensitivity and acute perception (traditional feminine attributes) with the masculine values of strength, courage and determination. Mulan earns military glory for her pivotal role in the defeat of the invading Hun army yet rejects it in favour of her family, whom she honours above all else. Finessa is an extraordinary character whose behaviour combines both traditional male and female attributes, which she uses to her own advantage.

In its employment of cross-dressing, children's literature toys with the social propensity to confuse sex and gender. The issue is concisely expressed by Woodhouse:

What do we see in the first few moments of an initial encounter with someone? We see their sex - at least w'e think we see their sex, but in fact we do not. What we see is their gender appearance and we assume that this is an accurate indication of their sex. Most people will feel completely certain of the biological sex of the majority of people they meet in their daily lives of work and leisure, they will feel sure gender appearance denotes biological sex; but they may be wrong. $(1989, \mathrm{p} .1)$

Compared with the more overt subversion expressed by contemporary adult transvestites, children's literature approaches the notion of challenges to gender identity in a more subtle manner. It presents a model, slightly unbelievable in terms of contemporary understanding, in which young women dress themselves as boys, escape an oppressive regime, prove themselves the equals of their male counterparts, and then revert to their former feminine positions. Their rebellious transgression is temporary. Cross-dressing heroines operating within the female-tomale paradigm enjoy a brief flirtation with transvestism, rather than an enduring love affair, yet its ultimate effects are impossible to measure. Although the cross-dressing ceases on a visible and physical level, its ultimate effects are somewhat unquantifiable. Having experienced what it is to be considered 'male', can the character resume a 'feminine' subject position? If they do so (as is usually the case), how will this subject position differ from the subject positions of other females because of the knowledge of what it is to be considered 'other' to such a gendered identity, and to have been granted the opportunity to view both male and female subject positions from an oppositional perspective? Each of these questions is posed by cross-dressing characters operative within the female-to-male children's cross-dressing schema, creating a unique forum for inquiries regarding the construction of gender categories.

Rather than merely presenting a world in which the artificial construction of gendered identities is analysed and exposed, children's literature uses transvestism as both a weapon of critique and an alternative to the constraining effects produced by gender divisions. Crossdressing/transvestism becomes the means through which gender can be positively subverted and re-appropriated by subjects to whom it does not holistically 'apply'. Female-to-male cross-dressing narratives in children's iterature thus become a catalyst for a radical re-evaluation of gender, and the role that it plays in the constitution of individual identity. Texts such as Alanna, Mulan, 'The Subtle Princess' and 'The Mouse, The Thing and The Wand' advocate a progressive approach of 'tolerance' to the issue of gender. Each rejects the limitations imposed upon individuals by an inflexible, bipolar system of gender, effecting dissatisfaction through the personification of a character who refuses to be categorised or defined according to convention. The cross-dressing subjects of these texts reclaim gender for themselves as they subvert, transgress, destabilise and rebel against traditional gender 'values'. Their 'gender' takes an ultimately unprecedented form. It becomes a 'third', against which 'masculinity' and 'femininity' are interwoven, merged and dissected through the rituals of performance. The female-to-male cross-dressing character of children's literature occupies a stage upon which all performative acts form a celebratory theatre of autonomous individualism, and the 'regulatory fiction' of gender assumes a role akin to that of a director. Although it lurks backstage, and is responsible for master-minding the production, the end result belongs very much to the actor. 


\section{NOTES}

1. 'The Counterfeit Marquise' is included in M. Warner, (ed) Wonder Tales. New York, Vintage, 1996, pp. 123-147.

2. 'The Subtie Princess' appears in M. Warner (ed) Wonder Tales, pp. 65-97.

3.'The Mouse, The Thing and The Wand' appears in S. Husain, Women Who Wear the Breeches - Delicious and Dangerous Tales, London, Virago, 1995, pp. 117-144.

4. The plot of 'The Subtle Princess' is as follows. Upon leaving for a journey, the king, her father, locks Finessa and her two sisters (both of whom are silly and selfish) in a tower, entrusting to each of them a magic glass bobbin which will break if they do anything dishonourable. A villainous prince breaks into the tower and tricks the two sisters into betraying themselves. Soon after, they give birth to two sons. Intent on revenge, Finessa disguises herself as a male doctor and outwits the crafty prince. Soon after she finds love in the arms of his younger brother, and is single-handedly responsible for preventing her own and her new husband's death, thus ensuring their eternal happiness.

\section{REFERENCES}

Butler, Judith (1990) Gender Trouble: Feminism and the Subversion of Identity. New York, Routledge.

Garber, Marjorie (1992) Vested Interests: Cross-dressing and Cultural Anxiety. London, Penguin.

Garber, Marjorie (1997) Vice Versa: Bisexuality and the Eroticism of Everyday Life. London, Penguin.

Gauntlett, D., 'Judith Butler', Theory, Gender and Identity Resources, http://www.leeds.ac.uk/ics/ctrb-el.htm.

Husain, Shahrukh (ed) (1995) Women Who Wear the Breeches: Delicious and Dangerous Tales. London, Virago.
Mulan (1998) The Walt Disney Company.

Osborne, P. and Segal, L., 'Gender as Performance: An Interview with Judith Butler, as appears in extracted form at the Theory, Gender and Identity Resources' homepage: http://www.leeds.ac.uk/ics/but-int1.htm

Pierce, Tamora (1983) Alanna: The First Adventure. New York, Random House.

Pierce, Tamora (1998) In the Hand of the Goddess, New York, Scholastic Children's Books.

Piggford, G. (1997) "Who's That Girl?": Annie Lennox, Woolf's Orlando and Female Camp Androgyny', Mosaic 30,3: pp.39-57

Stephens, John and McCallum, Robyn (1998) Retelling Stories, Framing Culture:Traditional Story and Metanarratives in Children's Literature. New York, Garland Publishing.

Young, S., 'Judith Butler', Theory, Gender and Identity Resources,http://www.leeds.ac.uk/ics/ctr-b-el.htm.

Warner, Marina (ed) (1996) Wonder Tales. New York, Vintage Books.

Westin, B. (1999) 'The Androgynous Female (or Orlando inverted): Examples from Gripe, Stark, Wahl, Pohl', in Pastemak, L. (ed) Gender in Children's Literature. Stockholm, Baitic Centre for Writers and Translators.

Woodhouse, Annie (1989) Fantastic Women: Sex, Gender and Transvestism. Basingstoke, Macmillan.

\section{BIOGRAPHICAL NOTE}

Victoria Flanagan currently works as a legal editor, and is also a contributing writer for the magazine $D V D$ Now. In 1999 she completed her English Honours at Macquarie University, and is now enrolled in a PhD focusing on representations of (trans) gender in children's literature. 